\title{
ENTREVISTA COM CARLOS GELORMINI LEZAMA
}

\author{
Por Elisângela Teixeira
}

\section{Could you explain to us why some languages have a system with two pronouns (an overt and a null pronoun)? What are the advantages of having two pronouns?}

Who knows? This is a question that cannot be answered yet. It may be the case that we will never know the answer. It may also be the case that the presuppositions that this question brings with it are not satisfied, in which case, the question should/could not be answered. Let me address three of these presuppositions, which might help me frame the answer to the question.

The first presupposition is that languages like Spanish, Italian or Portuguese contain null pronouns, that is, phonologically null expressions that supposedly occupy a position regularly occupied by overt pronouns. This has never been proved. What we have are sentences that contain a verb and its complements. Saying that a sentence "lacks" a subject is already based on the incorrect assumption that a sentence "should" contain a subject. Most sentences I produce in my Spanish "lack a subject", in that sense. We could also say that my sentences do not lack anything, or that they lack everything that they do not have. So this first presupposition could be summarized as "there is something null".

The second presupposition is that if a sentence "lacks a subject", that null element is a pronoun. So first, we claim that there is something silent, and now we add something to that, and claim that the element that is silent is a pronoun. Because pronouns are pro-forms, we might as well call "null pronouns" "null pro-pronouns" with a double "pro", because these forms are claimed to be in the place of a pronoun, a form which is in its 
turn in place of another category (a noun/determiner phrase). The idea that null pronouns exist is based on the model of languages like English. This may have been good at some point in the research agenda of many linguists. I do not think this is the case anymore. Chomsky recently said that Italian, and I add Spanish, do not contain null pronouns and that this kind of analysis tends to forget that English is not a very normal language, it is the exception rather than the norm. Expletives are very unusual crosslinguistically. He explicitly says that Italian does not satisfy the Extended Projection Principle (EPP). This is not a problem for Italian or Spanish. This is a problem for his theory. This was solved by claiming that there exist null pronouns. Maybe because Chomsky is getting old and wiser he wants to assume as little as possible now and he is not fearful. Null pronouns may not exist at all. Incidentally, I never quite understood why sentences that lack a subject cannot be said to contain "null nouns", "null repeated names", "null definite phrases", etc. Why should it be a pronoun? If there is nothing there, how do we know it is a pronoun? Because it could be replaced by a pronoun? A pronoun replacing a pronoun? It could also be replaced by a noun phrase or a noun clause. So, I find the idea that "null pronouns" exist at all rather controversial.

The third presupposition is that having more elements is an advantage. Linguists use the expression "rich" when they mean "more". So they say that the English vocalic system is richer than the Spanish system and that the Spanish morphological verbal system is richer than the English one. But I am not sure this is the case. What might be an advantage for communication, might be a disadvantage from a computational point of view, so I do not know. Some researchers think that there is a division of labor between overt and null pronouns. Null pronouns pick up subject antecedents and overt pronoun pick up object antecedents. But this is an oversimplification.

Now, let me try to answer your question. I do not know why some languages have a two pronoun system and others do not. I am not sure this is a correct description of the facts because of the assumptions I just addressed. However, assuming for one moment that a language 
like Spanish does in fact contain null pronouns, I have no idea why this should be the case and why a language like English should be different in this respect. This question is not new. It lies at the heart of the Principles and Parameters theory. Why do parameters exist at all? Why does UG display two options? Why not three? Why not just one? And if we pursue this line of reasoning we could even end up asking: why is there more than one language in the world? The honest answer might just be that things are the way they are for no particular reason. But researchers are paranoid for we always think there is a reason for everything. In that, we resemble 4 year old kids, always asking "why"?

\section{Could you tell us something about the linguistic concepts involved in the Repeated Name Penalty (RNP) and Overt Pronoun Penalty (OPP)? Do you think the RNP and the OPP could reveal any new information about the nature of language?}

"John is happy" is read slower after "John loves Mary" than after "Mary loves John". That's the RNP. "He is happy" is read slower after "John loves Mary" than after "Mary loves John". That's the OPP. This OPP happens in Spanish, Portuguese, and probably Italian, that is, languages where the EPP does not need to be satisfied (or where the EPP is satisfied by means of null pronouns). The RNP happens in every language that has been studied so far. It might be that both the RNP and the OPP are two epiphenomena of the same underlying principles.

However, as I said, the RNP and OPP are just phenomena: slower reading of sentences. The questions we should address are why, when and how the RNP and the OPP occur. Importantly, we should investigate why, when and how the RNP and the OPP are eliminated. It is worth remembering that both the RNP and the OPP are interaction effects in the sense that they do not always occur as shown by the works of Gordon, Almor, and myself.

I would like to emphasize here that in order to study these processing delays, we should not just ask ourselves what type of anaphor we should 
compare. A very important, crucial point is to understand that these are interaction effects, where the type of anaphor is one of the two factors. The second, sometimes neglected factor is the discourse prominence of the entity referred to by the antecedent. Without a reference to this second factor, it makes no sense to talk about the RNP or the OPP.

\section{Do you think that the RNP can be considered as a principle in terms of the Principle and Parameters Theory to be applied out of the scope of a sentence?}

The RNP is a phenomenon, so I do not think it could be claimed to be a principle. Principles can be defined as rules of grammar that are universal, common to all languages. But the RNP is not a rule. RNP contexts do not render sentences ungrammatical or unacceptable. They just make you read them a little bit more slowly. Now, it may be that there is some general and universal principle that underlies the RNP (and maybe the OPP) too. Researchers like Almor have suggested a pragmatic explanation for this kind of processing delays. This brings the RNP and the OPP together, as two manifestations of the same underlying principle. However, this does not mean that this principle would be a principle in the sense of the Principles and Parameters Theory. It could be a manifestation of a general preference of our human mind which happens outside language domains as well. The processes involved in reading a sentence include factors as diverse as the intensity of the light in the room, how noisy your neighbors are, and how drunk you are at the moment of reading. So, coming to conclusions about universals when we are dealing with performance rather than competence is quite hard. The Principles and Parameters Theory provides a model of internal (I) language, not a model of comprehension or production.

Let us consider the following two sentences:

(1) *John $n_{\mathrm{i}}$ said that $\mathrm{John}_{\mathrm{i}}$ is tired

(2) $\mathrm{He}_{\mathrm{i}}$ said that he $\mathrm{i}_{\mathrm{i}}$ is tired 


\section{Could we relate the first one with the RNP and the second one with the OPP? If so, how to explain that the second one is grammatical? Is the second one grammatical in pro-drop languages?}

Yes, I think it makes sense to make this comparison. According to the old Binding Theory, sentence (1) is ungrammatical because it violates Principle C, which states that R-expressions should be free. Sentence (2), on other hand, is grammatical because the pronoun is free in its binding domain, in this case, the "that-noun clause".

Now, here I see a gradient of unacceptability, at least in my Spanish. Sentence (2) is grammatical but one would expect it to generate an OPP. It is grammatical but worse than "He said that (...) is tired", with a null pronoun (or as I like to say now, without a pronoun). In Spanish, the presence of an overt pronoun in (2) seems to be pragmatically determined.

Sentence (1) appears to violate Principle C and it is indeed pretty bad. However, one could think of examples where this sentence could be used. So, here one could think that the sentence is bad in terms of both the RNP and Principle C.

Now, consider a sentence like (3) below:

$(3)^{*}$ Juan ${ }_{i}$ lo $_{i}$ ama

John him loves

John loves him

This sentence is far worse than (1), unless of course we eliminate the coindexation, in which case the sentence is perfectly grammatical. If the object pronoun "lo" is bound by "Juan" then the sentence is unacceptable. This is significantly worse than (1).

So I suppose we could relate (1) to the RNP suggesting this ungrammaticality exists but is not as bad as (3). We could also relate (2) to the OPP suggesting this is an OK sentence which would cause 
some difficulty in processing. An important point to remember is that RNP and OPP contexts should be perfectly grammatical; otherwise the processing delay would be unsurprising.

In Brazilian Portuguese (BP), two independent studies reached different conclusions about the RNP. The first one (Leitao, 2005, 2008, 2012) shows the occurrence of RNP in Portuguese, while the other one does not (Maia; Cunha-Lima, 2012). What is your opinion about this controversy?

There is no controversy. There is no difference. They are talking about two different things and using the same term "RNP". Some are talking about the comparison of sentences containing repeated names and sentences containing overt pronouns. Some are talking about the comparison of sentences containing repeated names and sentences containing null pronouns. Many times, I have tried to explain that we are trying to solve a problem that does not exist and that we are dealing with a false controversy but I may not have made my point very clearly.

I wrote an article for a Brazilian journal in which I explain this topic with some detail. Basically there is a terminological problem. Now, which of the two comparisons should deserve the name of the RNP in null subject languages, well, that is debatable and may not be very relevant from a scientific standpoint. It is a little bit like discussing whether it would be better to change the name of Principle A of Binding Theory into Principle 1, or Principle Anaphor. This would not change what the Principle A states and the (relative) truth behind it.

Similarly, let us assume for a moment (mistakenly) that we accept that the RNP in null subject languages should be about the comparison of sentences containing repeated names and sentences containing over pronouns. Well, the important thing here is whether this difference exists, not the name we employ to refer to it. There are two possible comparisons, so instead of discussing which of the two deserves the name of the RNP, why do we not just come to an agreement with respect to what we are going to call each of the two? 
Let's us consider $\mathrm{BP}$ as a pro-drop language, even though some scholars argue in favor of a parameter change. In this case, in order to investigate the RNP in BP, we should compare a repeated name with a null pronoun or a repeated name with an overt pronoun? Could you explain us the reasons for your choice?

This is related to what I was just saying. We can compare whatever we want. We can go to the world with our GoPro cameras and record every single event in the world, measure them, and try to come up with a model that will fit the data. There is a problem with this. We will not learn a thing. This is absolutely useless but this is what most researchers do, nowadays. However, if you look at the history of science, you will learn that, for example, uniform circular motion was not discovered after recording 17,248 objects moving in a circular fashion and that, similarly, Newton did not need to see more than just one apple falling from a tree to come up with the crazy idea of the law of gravity.

But let me go back to the question: if you believe the RNP is the comparison between repeated names and null pronouns, that's what you should measure, and if you think that the RNP is the comparison between repeated names and overt pronouns, you should measure those. In reality, we always measure both, so it is not a big deal anyway. However, a good way to stop talking about which should be called the RNP would be to say that in English there is only one RNP, the one that results from the comparison between sentences containing repeated names and sentences containing pronouns. In null subject languages there is an RNP1, which is the comparison between sentences with repeated names and sentences with overt pronouns, and an RNP2, which is the comparison between sentences with repeated names and sentences with null pronouns. Trying to win the discussion over which is the "real RNP" (RNP1 or RNP2) might not be worthwhile.

Now there have also been, I think, some interesting, mixed findings with respect to these two kinds of RNP in Brazilian Portuguese. Some authors claim there is an RNP1 whereas some authors (like me) claim 
that there is only an RNP2. This needs to be further studied. This could reveal something about the processing of (overt) pronouns in null subject languages. Spanish overt pronouns appear to be processed more like English repeated names than like English pronouns. In this sense, since terminological debates seem to be so attractive to us, I might go ahead and suggest that overt pronouns in Spanish should not be called pronouns at all. Or at least, we should make it clear that they behave very differently from pronouns in non pro drop languages.

Recebida em 30/09/2014

Aprovada em 06/10/2014 